\title{
Dentine caries excavation: a review of current clinical techniques
}

\author{
A. Baneriee, ${ }^{1}$ T. F. Watson, ${ }^{2}$ and E. A. M. Kidd, ${ }^{3}$
}

\begin{abstract}
Since the invention and application of rotary instruments, the operative treatment of carious lesions has often resulted in considerable removal of tooth structure. More recently, newer techniques for removal of carious dentine have been developed in an attempt to minimise this excessive tissue loss. The following article reviews and discusses some of the techniques available to excavate demineralised dentine clinically. These methods can be classified as mechanical and non-mechanical, rotary and non-rotary and include: dental handpieces/burs, manual excavators, air-abrasion, air-polishing, ultrasonication, sono-abrasion, chemo-mechanical methods, lasers and enzymes. The advantages and disadvantages of each technique are discussed.
\end{abstract}

$\mathrm{T}_{\mathrm{r}}^{\mathrm{h}}$ he techniques used in carious dentine 1 removal have developed since GV Black, in 1893, initially proposed the principle of 'extension for prevention' in the operative treatment of carious lesions. He proposed that the removal of sound tooth structure and anatomical form at sites that might otherwise encourage plaque stagnation (eg occlusal fissures, approximal contact points) would help minimise caries onset and progression. These principles of cavity preparation were based on the clinical presentation of caries and constrained by the knowledge of the disease process and the restorative materials available at that time. However, in more recent years, with the advent of adhesive restorative materials and the subsequent developments in minimal cavity design, this widely accepted principle has been challenged and is now considered too destructive a method for caries removal. ${ }^{1}$ Latest theories regarding the rationale of carious dentine removal are also

\footnotetext{
$1^{*}$ Clinical Lecturer, Conservative Dentistry, ${ }^{2}$ Reader in Microscopy and Biomaterials in Dentistry,

${ }^{3}$ Professor of Cariology, Division of Conservative Dentistry, Guy's, King's and St. Thomas' Dental Institute, KCL, London

Correspondence to: Dr A Banerjee, Division of Conservative Dentistry, Floor 26, Guy's Tower, GKT Dental Institute, London Bridge, London SE1 9RT email: avijit.banerjee@kcl.ac.uk REFEREED PAPER

Received 09.09.99; ACCEPTED 27.01.00

(C) British Dental Journal 2000; 188: 476-482
}

beginning to question the amounts of tissue that need to be excavated in order to successfully treat a carious lesion. ${ }^{2,3}$

When removing demineralised dentine it is not always easy to know at what point to stop excavation because there is an apparent lack of objective clinical markers. Figure 1 shows a longitudinal cross-section through a typical occlusal and approximal dentine
Fig. 1 Reflected light photomicrograph of a longitudinallysectioned, approximal and occlusal lesion showing colour gradations from the heart of the lesion (subjacent to the EDJ) to the advancing lesion front (TD - translucent dentine). Scale bar = $1 \mathrm{~mm}$ lesion with the colour gradations clearly evident. What these colour changes mean in terms of the demineralisation process and the level of infectivity is not entirely clear. The clinician tends to rely on the consistency of the tissue while the researcher may now use the autofluorescence of carious dentine as a reproducible, objective, histological, in vitro marker allowing clinically relevant comparisons between excavation techniques to be made. ${ }^{3-6}$

\section{Tissue removal techniques}

There are a number of techniques available for cutting tooth tissue (see Table 1). Some claim to remove demineralised dentine selectively whereas others are not able to make this distinction and indeed, may not even be able to remove softened tissue effectively. For this reason it is important that the practitioner knows what might be expected from these various techniques and this review intends to provide the reader with such information.

The ideal cutting instrument should fulfil certain factors to satisfy both operator and patient. These factors might include:

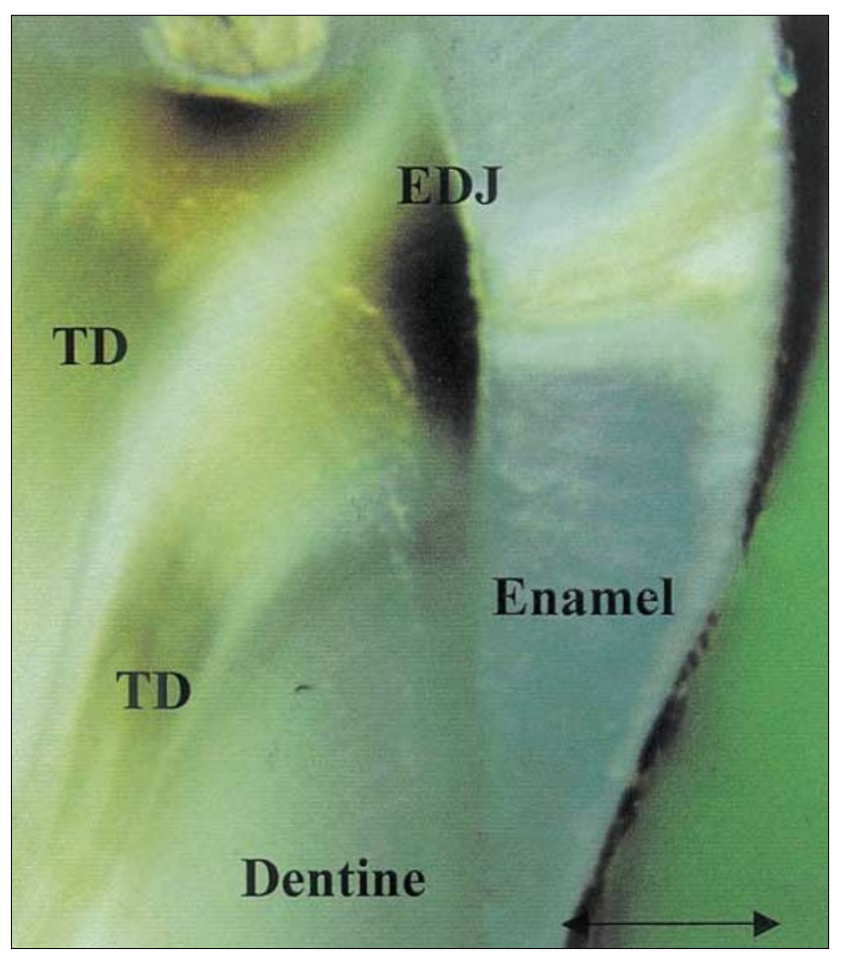




\section{Table 1 Clessification of vorious tooth-cuthing techniques \\ Category \\ Mechanical, rotary \\ Mechanical, non-rotary \\ Chemo-mechanical \\ Photo-ablation}

- Comfort and ease of use in the clinical environment

- The ability to discriminate and remove diseased tissue only

- Being painless, silent, requiring only minimal pressure for optimal use

- Not generating vibration or heat during periods of operation, and

- Being affordable and easy to maintain.

No mechanical method at present benefits from all these attributes. Indeed, clinical progress in this field seems, relatively speaking, to be lagging behind that in restorative material science and even the theory and rationale of caries treatment.

\section{Excavators, handpieces and burs}

The history and development of these instruments have been reviewed comprehensively in papers by Stephens, Crawford and Siegel and Fraunhofer and therefore will not be discussed further in this paper. $^{7-9}$

Even though the rotary bur is in universal use, there are still problems that need to be overcome. Five factors are potentially responsible for the discomfort and pain that is associated with cavity preparation: ${ }^{10,11}$

- The sensitivity of vital dentine

- Pressure on the tooth (ie mechanical stimulation),

- Bone-conducted noise and vibration

- The high-pitched noise of the air-turbine handpiece, and

- Development of high temperatures at the cutting surface (ie thermal stimulation).

Several studies have showed that temperatures at the cutting surface of burs and stones could easily rise above the pain threshold and, even with water spray lubrication, some damage to the underlying pulp might still occur. ${ }^{12-15}$ The rotating bur easily cuts through carious dentine to eventually open up healthy tubules deeper in the tissue and in conjunction with water stimulation of odontoblast processes, this will result in the pain associated with cavity preparation using this technique. Even if the operator maintains continuous bur movement over a large surface area and keeps the bur speed and pressure constant throughout use, the type and size of bur used (for example, a large diameter round bur) can all help to reduce these detrimental factors to some degree; however, they are not completely eradicated and thus still pose a significant problem. In current practice, having gained access to the carious dentine using the high-speed air turbine handpiece and bur, the slow-speed bur or hand excavator can be used for carious dentine excavation. As the hand excavator will remove softened tissue with more sensitive tactile feedback than a bur, this method is the more self-limiting of the two.

\section{Air-abrasion}

Air-abrasion was originally developed by RB Black in 1945 who instigated preliminary investigations into an alternative pseudo-mechanical method for dental tissue removal which involved bombarding the tooth surface with high-velocity particles (conventionally aluminium oxide $\left(\mathrm{Al}_{2} \mathrm{O}_{3}\right)$ ) carried in a stream of air. ${ }^{16}$ Depending on the nature of the abrasive used, this technique has the ability of abrading efficiently both sound dentine and enamel. There are several parameters that can be altered in order to adjust the cutting characteristics of the instrument: the type and size of abrasive particle will affect the coarseness of the abraded surface - the larger the size and harder the particles, the greater is the transferred kinetic energy to the surface and thus the rougher the final finish. The speed of the particles altered by varying the air pressure, the distance between the nozzle and tooth surface and the length of cutting time will also play an important part in adjusting the effectiveness of the instrument - reduced velocity will reduce the transferred kinetic energy to the tooth surface thus reducing the overall abrasiveness of the system. ${ }^{10,17,18}$ The first units to be commercially manufactured were the Airdent machines. Early patient surveys indicated that this technique was greatly favoured by patients and dentists alike. ${ }^{19-22}$ This method of cutting teeth seemed to dramatically reduce the problems of heat generation, ${ }^{15}$ vibration and other mechanical stimulation ${ }^{10,17,22}$ resulting in relatively pain-free procedures when compared with the dental drill. There have been reports to indicate that there were no significant differences in pulpal response between air abrasion and high-speed bur preparation using copious water spray. ${ }^{23}$

Air-abrasion has been used for several different applications within the field of restorative dentistry including removal of external stains and calculus, minimal cavity preparations, crown preparations and fissure sealant/preventive resin restoration placement. ${ }^{11,16,22,24-27}$ Note that to date, these applications using commercially available alumina abrasive do not include the efficient removal of softened, carious dentine. Disadvantages of the technique include the total loss of tactile sensation whilst preparing the cavity because the nozzle does not touch the surface of the tooth. This, coupled with the fact that the operator must be able to envisage the position of the cavity boundaries prior to cutting, leads to the significant risks of cavity over-preparation and inadequate carious dentine removal. ${ }^{26-28}$ It must be emphasised that the aluminium oxide abrasive particles will remove sound enamel and dentine very efficiently, whereas 
clinically soft, carious dentine is not removed due to the reduced hardness of the carious substrate when compared with the alumina particles themselves. ${ }^{3}$ There is also the potential of inhalational problems, with studies from the 1950s showing evidence of chronic granulomatous reactions, patchy atelectasis and emphysematous changes in rabbits' lungs after particle inhalation. ${ }^{29,30}$ However, no reference was made to the size of the inhaled particles in either paper. In 1952, Van Leeuwen and Rossano performed experiments using particles of $40 \mu \mathrm{m}$ diameter. This size was well above the size considered injurious from a respiratory standpoint. They concluded that on a basis of dust counts, particle size and composition, the normal use of an air abrasive unit presents little health hazard to patient and dentist. ${ }^{31}$ The technique at present has full US FDA approval for clinical use of $27.5 \mu \mathrm{m}$ alumina particles.

Recent advances in microabrasion technology allow a metered flow of alumina particles, higher operating pressures and almost instantaneous initiation and termination of the abrasive stream. Further investigation into the use of alternative abrasive mixtures has indicated that softer particles, eg polycarbonate resin or alumina-hydroxyapatite mixtures might be more selective in carious dentine removal as they are only capable of removing tissue of equivalent hardness, leaving healthier, sound tissue virtually unscathed. ${ }^{3,32,33}$ These factors, coupled with the use of protective rubber dam, barrier masks for the clinical team, more efficient suction units to expel the unwanted dust and rapid progress in the development of adhesive restorative materials with consequent changes in cavity design, might allow the air-abrasive technique to make a comeback in the dental surgery of the future. ${ }^{1,34}$

\section{Air-polishing}

Air-polishing is the process by which watersoluble particles of sodium bicarbonate, to which has been added tricalcium phosphate ( $0.08 \%$ by weight) to improve the flow characteristics, are applied onto a tooth surface using air pressure, shrouded in a concentric water jet. ${ }^{35,36}$ This is the important difference between this technique and that of air- abrasion. The fact that the abrasive is water soluble means it does not escape too far from the operating field. ${ }^{37}$ The bombardment of the hard tooth surfaces by these particles results in a continuous mechanical abrasive action which removes surface deposits. ${ }^{38}$ Razzoog and Koka noted that increasing the air pressure beyond 90 psi actually reduced the abrasiveness of the Microprophy System (Danville Engineering Co., Danville, CA). This was due to a phenomenon found in one-dimensional, twophase fluid dynamics - 'choked flow'. In this scenario, as the air pressure exceeds the critical pressure, the mass flow of particles will reduce thus limiting the system's abrasiveness. ${ }^{39}$ The commercially recommended use of this technique is to remove surface enamel stains, plaque and calculus well away from the gingival margins of healthy teeth. ${ }^{35}$ However, due to the non-selective, abrasive, detrimental surface attack of restorations and sound enamel and dentine, overzealous use could easily remove a considerable amount of healthy tooth structure especially at the cervical margin. ${ }^{40,41}$ It has been suggested that air-polishing could be used for the removal of carious dentine at the end of cavity preparation. ${ }^{37}$

\section{Ultrasonic instrumentation}

Investigation of this technique has been confined to work carried out in the 1950s where studies by Nielsen et al. indicated the possibility of using an ultrasonic instrument to cut tooth tissue. ${ }^{42,43} \mathrm{He}$ designed a magnetostrictiv instrument with a $25 \mathrm{kHz}$ oscillating frequency. This, used in conjunction with a thick aluminium oxide and water slurry, created the cutting action, the mechanism of which was the kinetic energy of water molecules being transferred to the tooth surface via the abrasive through the high speed oscillations of the cutting tip. It was found that the harder the tissue, the easier it was to cut. Soft, carious dentine apparently could not be removed, but the harder, leathery, deeper layer was more susceptible. ${ }^{42,43}$ However, in light of current knowledge regarding the structure of the carious lesion in dentine, it is a debatable point as to whether this harder, leathery, deeper surface should actually be removed as it probably represents the dentine that has been affected by the carious process but only minimally infected, with a collagen structure permitting remineralisation. There are many parameters that could potentially be adjusted to alter the cutting characteristics and Nielsen attempted to analyse the results from altering the pressure applied, the length of use of the instrument, the powder : water ratio in the slurry, the nature of the material cut and the type of abrasive used. However, due to the erratic and unpredictable performance of the instrument, his results were inconclusive. ${ }^{43}$ Even though this method was developed only to a preliminary stage, it was used on forty patients in a clinical trial where they found the technique to be favourable in terms of the reduced vibration and sound generated when compared with the dental drill. ${ }^{44}$

\section{'Sono-abrasion'}

A recent development from the original ultrasonics mentioned above is the use of high-frequency, sonic, air-scalers with modified abrasive tips - a technique known as 'sono-abrasion'. The Sonicsys micro unit, designed by Drs Hugo, Unterbrink and Mösele in a venture between IvoclarVivadent and KaVo (KaVo Dental Ltd, Amersham, Bucks, UK), is based upon the Sonicflex 2000L and 2000N air-scaler handpieces that oscillate in the sonic region $(<6.5 \mathrm{kHz}$ - see Figure 2). The tips describe an elliptical motion with a trans-

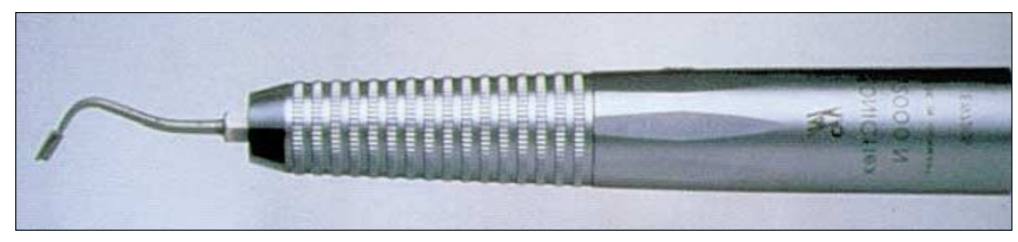

Fig. 2 KaVo Sonicflex 2000L air-scaler handpiece with diamond-coated tip 


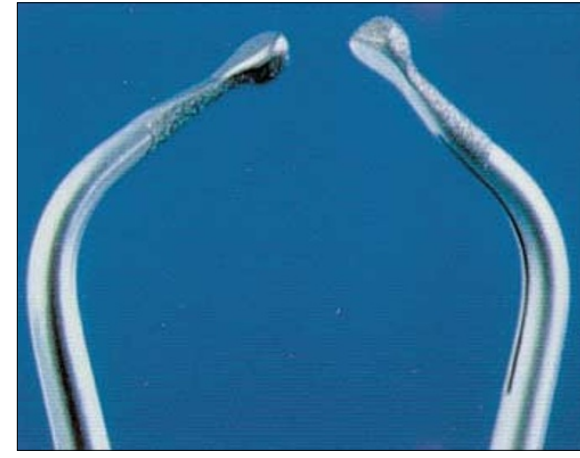

Fig. 3 Sonicsys micro diamond-coated hemispherical cutting tips

verse distance of between $0.08-0.15 \mathrm{~mm}$ and a longitudinal movement of between $0.055-0.135 \mathrm{~mm}$. They are diamond coated on one side using $40 \mu \mathrm{m}$ grit diamond (figure 3 ) and are cooled using water irrigant at a flow rate of between $20-30 \mathrm{~mL} /$ $\mathrm{min}$. The operational air pressure for cavity finishing should be around 3.5 bar (ie the nominal pressure at the coupling). There are currently three different instrument tips: a lengthways halved torpedo shape (9.5 $\mathrm{mm}$ long, $1.3 \mathrm{~mm}$ wide), a small hemisphere (1.5 mm diameter) and a large hemisphere $(2.2 \mathrm{~mm}$ - Figure 3$)$. The torque applied to the instrument tips should be in the region of $2 \mathrm{~N}$. If the applied pressure is too great, the cutting efficiency is reduced due to damping of the oscillations. This technique was initially developed, using different shaped tips, to help prepare predetermined cavity outlines (Sonicsys approx) but also works well in removing hard tissue when finishing cavity preparation. Favourable results from laboratory studies using sono-abrasion to remove softened, carious dentine have indicated another possible use for this technique in the future. 3,33

\section{Chemo-mechanical methods: Caridex and Carisolv}

In the previous sections, various mechanical methods of tooth tissue removal have been discussed. There is, however, another alternative and in 1976, Goldman and Kronman reported on the possibility of removing carious material chemically using N-monochloroglycine (NMG, GK-101). ${ }^{45}$
Subsequently, after modification, the Caridex system, containing N-monochloroD,L-2-aminobutyrate (NMAB, GK-101E), was introduced. ${ }^{46}$ This system was developed as a chemico-mechanical method for caries removal. Carious dentine, softened further by NMAB (GK-101E), should have been readily removed by lightly abrading its surface with the applicator tip. Several early studies found the technique to have advantages including increased patient compliance and a reduced need for local anaesthesia. ${ }^{47,48}$ Brannström et al. showed it to be a successful way of removing soft carious dentine without any significant damage to the underlying dentine, ${ }^{49}$ but other studies showed no beneficial effect of the system in excavating carious dentine when compared with a control system using water alone, no reduction in operating time and the need for copious volumes of solution. ${ }^{50}$ Further studies also indicated that in permanent teeth, the ability of carious dentine removal using NMAB was no greater than that using a control solution of isotonic saline. In deciduous teeth, however, addition of urea to the solution significantly improved carious dentine excavation compared with the same control solution without urea. ${ }^{51,52}$

Following on from this a gel-based system was developed and recently Carisolv gel has been introduced, to be used with specially designed non-cutting hand instruments to abrade the carious dentine surface. Carisolv consists of two carboxymethylcellulosebased gels: a red gel containing $0.1 \mathrm{M}$ amino acids (glutamic acid, leucine and lysine), $\mathrm{NaCl}, \mathrm{NaOH}$, erythrosine (added in order

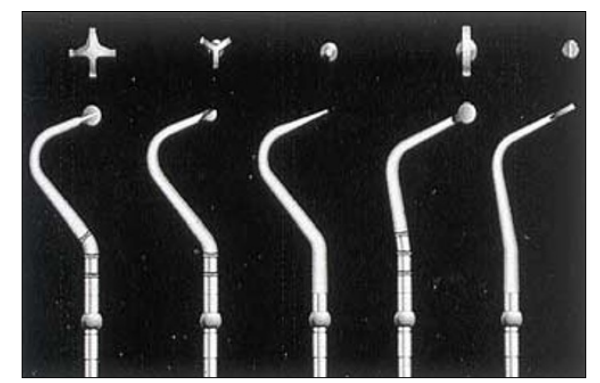

Fig. 4 Diagram of the cutting tips of the hand instruments supplied with Carisolv gel to make the gel visible during use); and a second containing sodium hypochlorite $(\mathrm{NaOCl}-0.5 \% \mathrm{w} / \mathrm{v})$. The two are thoroughly mixed in equal parts at room temperature before use and then applied, using the hand instrument, onto the exposed carious dentine and left for 60 seconds prior to gently but firmly abrading away the softened dentine to leave a hard, caries-free cavity. The solution has a $\mathrm{pH}$ of around 11 and it is postulated that the positively and negatively charged groups on the amino acids become chlorinated and further disrupt the collagen crosslinkage in the matrix of the carious dentine. The gel consistency will allow the active molecules access to the dentine for a longer period than the equivalent irrigating solution in the Caridex system. It is also highly probable that the gel has a mechanical lubricating action for the hand instrument which will also aid in the removal of the softened tissue. Early results from clinical trials indicated an increased patient compliance to this technique over the use of the dental drill to excavate carious dentine. ${ }^{53}$ However, drawbacks may include the prolonged operating time (when compared with rotary instrumentation) and the simple fact that the more conventional rotary methods are still necessary in order to gain access to the carious dentine to allow the gel to function. Therefore, the technique may only be useful in certain lesions e.g. exposed carious buccal, cervical root lesions or grossly cavitated, deep lesions in an attempt to minimise pulp exposures. Results from initial lab-based experiments testing its efficiency and effectiveness have shown this technique to have the potential to be a more selective method of carious dentine removal. ${ }^{3,54,55}$ It also appears to produce a cavity with an incomplete smear layer with open tubules evident. ${ }^{44}$ This point may have clinical relevance to the dentine bonding ability of adhesive materials and requires further investigation.

\section{Lasers - for the future?}

Since the development of the first ruby laser by Maiman in 1960, researchers postulated that it could be applied to cutting both hard and soft tissues in the mouth. However, early studies found that the ruby laser pro- 


\begin{tabular}{|c|c|c|c|c|c|}
\hline Table 2 & \multicolumn{5}{|c|}{ The relative ability of the various excavation techniques to remove tooth tissue } \\
\hline Method & $\begin{array}{l}\text { Sound } \\
\text { enamel }\end{array}$ & $\begin{array}{l}\text { Sound } \\
\text { dentine }\end{array}$ & $\begin{array}{l}\text { Carious } \\
\text { enamel }\end{array}$ & $\begin{array}{l}\text { Carious } \\
\text { dentine }\end{array}$ & Notes \\
\hline $\begin{array}{l}\text { Hand } \\
\text { excavators }\end{array}$ & - & - & + & ++ & \\
\hline Rotary burs & +++ & +++ & +++ & +++ & $\begin{array}{l}\text { Air-turbine and } \\
\text { slow-speed } \\
\text { handpieces }\end{array}$ \\
\hline Air-abrasion & +++ & +++ & ++ & + & $\begin{array}{l}\text { Depends upon } \\
\text { abrasive agent } \\
\text { used }\end{array}$ \\
\hline Air-polishing & + & + & + & - & $\begin{array}{l}\text { Requires hard } \\
\text { surface substrate } \\
\text { for abrasion }\end{array}$ \\
\hline Ultrasonics & + & + & + & - & $\begin{array}{l}\text { Retrograde root } \\
\text { filling cavity } \\
\text { preparation }\end{array}$ \\
\hline Sono-abrasion & - & + & + & ++ & $\begin{array}{l}\text { Further work } \\
\text { required }\end{array}$ \\
\hline $\begin{array}{l}\text { Caridex/ } \\
\text { Carisolv }\end{array}$ & - & - & - & +++ & $\begin{array}{l}\text { Still requires } \\
\text { conventional } \\
\text { access to dentine }\end{array}$ \\
\hline Lasers & + & + & + & + & $\begin{array}{l}\text { Depends on } \\
\text { wavelength, } \\
\text { intensity, pulse } \\
\text { duration etc. }\end{array}$ \\
\hline Enzymes & - & - & - & + & $\begin{array}{l}\text { Further work } \\
\text { required }\end{array}$ \\
\hline
\end{tabular}

duced significant heat that caused damage to the dental pulp. ${ }^{56}$ Since these early beginnings, the field of lasers has developed considerably and many new types of laser are available to cut dental hard tissues. The efficacy of the lasers will depend on numerous factors including the wavelength characteristics, pulse energy, repetition rate and the optical properties of the incident tissue. ${ }^{57,58}$ Lasers that are currently being investigated for more selective hard tissue ablation include:

- Er:YAG (erbium: yttrium-aluminiumgarnet) and Nd:YAG (neodymium: YAG) — mid-IR to IR emission
- Carbon dioxide lasers $\left(\mathrm{CO}_{2}\right)$ - IR emission

- Excimer lasers (ArF (argon:freon) and $\mathrm{XeCl}$ (xenon:chlorine) — UV emission

- Holmium lasers

- Dye-enhanced laser ablation — exogenous dye, indocyanine green in conjunction with a diode laser. ${ }^{56}$

In terms of carious dentine removal, the UV emission of excimer lasers ( $377 \mathrm{~nm}$ ) has the potential to be more selective in the ablation of carious dentine and there may be a possible use of dye-enhanced laser ablation to develop this selectivity further. ${ }^{57}$ In addition to caries removal, studies have shown that, in the presence of a suitable photo-sensitiser, low-power laser light has the ability to destroy Streptococcus mutans. ${ }^{59}$ Lasers have also been used to cut and seal dentine tubules, reducing the possibility of postoperative sensitivity. ${ }^{60}$ At present, there is significant interest in these instruments but problems still persist regarding thermal irritation to the pulp, the control of the procedure and the possible alteration/destruction of the adjacent sound tissue. These factors coupled with the expense and size of the equipment have meant their use in general practice as a hard tissue cutting tool has been effectively limited to date. 


\section{Enzymes}

Studies have examined the possibility that carious dentine might be able to be removed by using certain enzymes. In 1989, Goldberg and Keil successfully removed soft carious dentine using bacterial Achromobacter collagenase, which did not affect the sound layers of dentine beneath the lesion. ${ }^{61}$ Also, a more recent study has used the enzyme pronase, a non-specific proteolytic enzyme originating from Streptomyces griseus, to help remove carious dentine. ${ }^{62}$ This might have significant clinical implications but further laboratory research is required for validation of this technique.

\section{Conclusions}

This paper has discussed and reviewed an extensive literature on alternative methods of removing caries and cavity preparation. The ability of the techniques to remove tooth tissue is summarised in Table 2. The main problem at present is the apparent lack of the 'self-limiting' nature of the individual methods. All the techniques will remove carious dentine with differing levels of efficiency but more importantly, it is still unknown if these techniques will discriminate between the soft, outer, necrotic, highly infected zone that needs to be excavated and the inner, reversibly damaged, less infected zone which could be retained. If this discrimination does not take place, this could still lead to overpreparation of cavities with little control over the quality and quantity of tissue removed by individual operators. There is, therefore, an important need to assess the effects of these techniques for their efficiency and extent of removal of carious dentine.

This work has been supported by the Medical Research Council in the form of a Clinical Training Fellowship (Grant No: G84/4339).

1 Elderton R J. New approaches to cavity design with special reference to the Class II lesion. $\mathrm{Br}$ Dent J 1984; 157: 421-427.

2 Mertz-Fairhurst E J, Curtis J W, Ergle J W, Rueggeberg F A, Adair S M. Ultraconservative and cariostatic sealed restorations: results at year 10. JAm Dent Assoc 1998; 129: 55-66.

3 Banerjee A. Applications of scanning microscopy in the assessment of dentine caries and methods for its removal. $\mathrm{PhD}$ Thesis, University of London 1999.

4 Banerjee A, Boyde A. Autofluorescence and mineral content of carious dentine: scanning optical and backscattered electron microscopic studies. Caries Res 1998; 32: 219-226.

5 Banerjee A, Watson T F, Kidd E A M. Relation between the autofluorescence and excavation of carious dentine. J Dent Res 1998; 77: 632

6 Banerjee A, Sherriff M, Kidd E A M, Watson T F. A confocal microscopic study relating the autofluorescence of carious dentine to its microhardness. Br Dent J 1999; 187: 206-210.

7 Stephens R R. The dental handpiece - a history of its development. Aust Dent J 1986; 31: 165180.

8 Crawford P R. The birth of the bur (and how a Canadian changed it all!). J Can Dent Assoc 1990; 56: 123-126.

9 Siegel S C, Fraunhofer J A. Dental cutting: the historical development of diamond burs. J Am Dent Assoc 1998; 129: 740-745.

10 Black R B. Airbrasive: some fundamentals. J Am Dent Assoc 1950; 41: 701-710.

11 Myers G E. The airbrasive technique: a report. Br Dent J 1954; 97: 291-295.

12 Henschel C J. Heat impact of revolving instruments on vital dentin tubules. J Dent Res 1943; 22: 323-333.

13 Anderson D J, Van Praagh G. Preliminary investigation of the temperatures produced in burring. Br Dent J 1942; 73: 62-64.

14 Beebe D M. Efficiency of high operating speeds with water lubrication in cavity preparation. $J$ Am Dent Assoc 1954; 49: 650-655.

15 Peyton F A, Henry E E. The effect of high speed burs, diamond instruments and air abrasive in cutting tooth tissue. J Am Dent Assoc 1954; 49: 426-435.

16 Black R B. Technic for non-mechanical preparations of cavities and prophylaxis. J Am Dent Assoc 1945; 32: 955-965.

17 Norton H D. The 'airdent' machine: some personal observations. Br Dent J 1951; 91: 268 269.

18 White H D, Peyton F A. Effects of air abrasive in prophylaxis. J Am Dent Assoc 1954; 49: 155163.

19 Goldberg M A. Airbrasive: patient reactions. J Dent Res 1952; 13: 504-505.

20 Morrison A H, Berman L. Evaluation of the airdent unit: preliminary report. J Am Dent Assoc 1953; 46: 298-303.

21 Gabel A B. Critical review of cutting instruments in cavity preparation. 3. Airbrasive technic. Int Dent J 1953; 4: 53-63.

22 Black R B. Application and revaluation of air abrasive technic. J Am Dent Assoc 1955; 50: 408-414.

23 Laurell K, Carpenter W, Beck M. Pulpal effects of airbrasion cavity preparation in dogs. J Dent Res 1993; 72: 273.

24 Epstein S. Analysis of airbrasive procedures in dental practice. J Am Dent Assoc 1951; 43: 578 582.

25 Burbach G. Micro-invasive cavity preparation with an airbrasive unit. GP 1993; 2: 55-58.

26 Goldstein R E, Parkins F M. Air-abrasive technology: its new role in restorative dentistry. I Am Dent Assoc 1994; 125: 551-557.
27 Goldstein R E, Parkins F M. Air-abrasive technology - authors' response. J Am Dent Assoc 1994; 125: 1164-1166.

28 Bailey L R, Phillips RW. Effect of certain abrasive materials on tooth enamel. J Dent Res 1950; 29: 740-748.

29 Fullmer H W, Eastman R F. Effect of aluminium oxide on the rabbit lung. J Dent Res 1952; 31: 487.

30 Kerr D A, Ramfjord S, Ramfjord G M. Effect of inhalation of air abrasive powder. J Dent Res 1954; 5: 666.

31 Van Leeuwen M J, Rossano A T. Dust factors involved in the use of the airdent machine. J Dent Res 1952; 31: 33-34.

32 Horiguchi S, Yamada T, Inokoshi S, Tagami J. Selective caries removal with air abrasion. $O p$ Dent 1998; 23: 236-243.

33 Banerjee A, Kidd E A M, Watson T F. Scanning electron microscopic observations of human dentine after mechanical caries excavation. $J$ Dent: in press.

34 Renson C E. Back to the future in cavity preparation. Dent Update 1995; 22: 93-95.

35 Horning G. Clinical use of air-powder abrasive. Compend Cont Educ Dent 1987; 8: 652-661.

36 Walmsley AD, Williams AR, Laird WRE. The air-powder dental abrasive unit - an evaluation using a model system. J Oral Rehab 1987; 14: 43-50.

37 Boyde A. Airpolishing effects on enamel, dentine and cement. Br Dent J 1984; 156: 287 291.

38 Atkinson D R, Cobb C M, Killoy W J. The effect of an air-powder abrasive system on in vitro root surfaces. J Periodontol 1984; 55: 13-18.

39 Razzoog M E, Koka S. In vitro analysis of the effects of two air-abrasive prophylaxis systems and inlet air pressure on the surface of titanium abutment cylinders. J Prosthod 1994; 3: 103107.

40 Newman P S, Silverwood R A, Dolby A E. The effects of an airbrasive instrument on dental hard tissues, skin and oral mucosa. Br Dent J 1985; 159: 9-12.

41 Lubow RM, Cooley RL. Effect of air-powder abrasive instrument on restorative materials. $J$ Prosth Dent 1986; 55: 462-465.

42 Nielsen A G, Richards J R, Wolcott R B. Ultrasonic dental cutting instrument: I. J Am Dent Assoc 1955; 50: 392-399.

43 Nielsen A G. Ultrasonic dental cutting instrument: II. J Am Dent Assoc 1955; 50: 399408.

44 Oman CR, Applebaum E. Ultrasonic cavity preparation II. Progress report. J Am Dent Assoc 1955; 50: 414-417.

45 Goldman M, Kronman JH. A preliminary report on a chemomechanical means of removing caries. J Am Dent Assoc 1976; 93: 1149-1153.

46 Schutzbank SG, Galaini J, Kronman JH, Goldman M, Clark RE. A comparative in vitro study of GK-101 and GK-101E in caries removal. J Dent Res 1978; 57: 861-864.

47 Anusavice K J, Kincheloe J E. Comparison of pain associated with mechanical and 
chemomechanical removal of caries. J Dent Res 1987; 66: 1680-1683.

48 Zinck JH, McInnes-Ledoux P, Capdeboscq C, Weinberg R. Chemomechanical caries removal - a clinical evaluation. J Oral Rehab 1988; 15: 23-33.

49 Brannström M, Johnson G, Friskopp J. Microscopic observations of the dentin under caries lesions excavated with the GK-101 technique. J Dent Child 1980; 47: 46-49.

50 Barwart O, Moschen I, Graber A, Pfaller K. Invitro study to compare the efficacy of $\mathrm{N}$ monochloro-D,L-2-aminobutyrate (NMAB, GK-101E) and water in caries removal. J Oral Rehab 1991; 18: 523-529.

51 Yip HK, Stevenson AG, Beeley JA. An improved reagent for chemomechanical removal of dental caries in permanent and deciduous teeth: an in vitro study. J Dent 1995; 23: 197-204.

52 Yip H K, Stevenson A G, Beeley J A.
Chemomechanical removal of dental caries in deciduous teeth: further studies in vitro. $\mathrm{Br}$ Dent J 1999; 186: 179-182.

53 Ericson D, Bornstein R, Götrick B, Raber H, Zimmerman M. Clinical multicentre evaluation of a new method for chemomechanical caries removal. Caries Res 1998; 32: 308.

54 Banerjee A, Watson T F, Kidd E A M. Carious dentine excavation using Carisolv gel: a quantitative, autofluorescence assessment using scanning microscopy. Caries Res 1999; 33: 313 .

55 Banerjee A, Kidd E A M, Watson T F. In-vitro evaluation of five alternative methods of carious dentine excavation. Caries Res; in press.

56 Adrian J C, Bernier J L, Sprague W G. Laser and the dental pulp. J Am Dent Assoc 1971; 83: 113117.

57 Wigdor H A, Walsh J T, Featherstone J D B, Visuri S R, Fried D, Waldvogel J L. Lasers in dentistry. Lasers in Surg Med 1995; 16: 103-133.

58 Seka W, Featherstone J D B, Fried D, Visuri S R, Walsh J T. Laser ablation of dental hard tissues: from explosive ablation to plasma-mediated ablation. SPIE 1996; 2672: 144-158.

59 Burns T, Wilson M, Pearson G J. Effect of dentine and collagen on the lethal photosensitisation of Streptococcus mutans. Caries Res 1995; 29: 192-197.

60 Mercer C. Lasers in dentistry: a review. Part 1. Dent Update 1996; 23: 74-80.

61 Goldberg M, Keil B. Action of a bacterial achromobacter collagenase on the soft carious dentine: an in vitro study with the scanning electron microscope. J Biol Buccale 1989; 17: 269-274.

62 Norbø H, Brown G, Tjan A H L. Chemical treatment of cavity walls following manual excavation of carious dentin. Am J Dent 1996; 9: 67-71. 